\title{
CINEMA-HISTÓRIA:
}

\section{Múltiplos aspectos de uma relação}

\author{
CINEMA-HISTORY: \\ history: multiple aspects of a relationship
}

José D'Assunção Barros ${ }^{1}$

\begin{abstract}
RESUMO: Dentro do âmbito de uma convergência entre História Cultural e História Política, este artigo busca esclarecer e discutir as várias possibilidades de interação e as relações possíveis entre História e Cinema, particularmente examinando o Cinema como fonte histórica, como meio para a representação historiográfica, como tecnologia de apoio para o trabalho historiográfico, e como agente que interfere no processo histórico. $\mathrm{Na}$ última parte do artigo, são apresentadas as modalidades fílmicas que conservam algum tipo de relação com a representação historiográfica.
\end{abstract}

Palavras-chave: Cinema; representação historiográfica; imagem.

\begin{abstract}
Inside the ambit of a convergence between Cultural History and Political History, this article attempts to clarify and discuss the several possibilities of interaction and the possible relations between History and Cinema, particularly examining the Cinema as historical font, as way for the historical representation, as technology to support the historiographyc work, and as an historical agent that interferes in the historical process. In the last part of the article they are presented the modalities of films that maintains relations with the historical representation.
\end{abstract}

Key Words: Cinema; historical representation; image.

Quando o historiador Marc Ferro cunhou a expressão Cinema-História, estava interessado em chamar atenção para os múltiplos aspectos de uma relação complexa, onde os dois termos da expressão interagem reciprocamente sem que um pese demasiado sobre o outro. Não se trata aqui, nem de considerar que a História se apropria de um objeto estático

\footnotetext{
${ }^{1}$ Historiador e Doutor em História pela Universidade Federal Fluminense. Atua como professor nos cursos de Graduação e Mestrado em História da Universidade Federal Rural do Rio de Janeiro (UFRRJ), e como Professor-Colaborador no Programa de Pós-Graduação em História Comparada da UFRJ. 
para ser analisado de forma unilateral, o Cinema, e nem, ao contrário, de uma relação onde o Cinema ocupa o centro do palco apenas iluminado pela História com suas abordagens e metodologias. Cinema e História, assim se pensava com a instituição de uma nova expressão que trazia para o centro das discussões uma relação complexa e interativa, tinham algo a ensinar e a transformar um no outro. O Cinema podia ensinar aos historiadores um novo modo de fazer a História e de representá-la, e a História podia ensinar ao Cinema um novo modo de seu auto-perceber historicamente e como fenômeno-processo em contínua transformação. Por fim, nessa relação de mútua transformação, Cinema-História constituiria algo novo, não apenas um novo objeto de estudo ou apenas um novo campo de saber, mas uma nova forma de examinar os seus termos e considerar o que um campo poderia incorporar do outro. O presente artigo pretende examinar esta relação na qual o Cinema se integra à História de múltiplas maneiras: como sujeito que interfere na própria História, como fonte para a compreensão desta mesma História, como meio para representar a História, como linguagem e tecnologia da qual pode se apropriar a História, para além, é claro, de um processo que pode ser ele mesmo historiado na perspectiva mais tradicional de uma História do Cinema.

A possibilidade de amadurecer uma nova noção complexa, contudo, tem sempre também a sua história, e neste caso esta história está diretamente relacionada à progressiva capacidade de um pólo se integrar ao outro, o que foi obra, certamente, de mais de um século de história ... e de cinema. Cinema e História, de fato, têm desenvolvido relações bastante íntimas desde que os primeiros filmes começaram a surgir por volta do alvorecer do século XX, e pode-se dizer que estes dois campos da atividade e da criação humana não cessaram de intensificar progressivamente suas possibilidades de interação à medida que o Cinema foi se firmando como a grande arte da contemporaneidade. Forma de expressão artística para a qual concorrem diversas outras artes - como a Música, o Teatro, a Literatura, a Fotografia e as demais Artes Visuais - o Cinema terminou por vir constituir a partir de si mesmo uma linguagem própria e uma indústria também específica, e ao par disto não cessou de interferir na história contemporânea ao mesmo tempo em que seu discurso e suas práticas foram se transformando com esta mesma história contemporânea. Eis aqui a raiz de um complexo jogo de interrelações possíveis que têm permitido que o Cinema se mostre simultaneamente como ‘fonte', ‘tecnologia', ‘sujeito’ e ‘meio de representação' para a História. 
No seu aspecto mais irredutível o Cinema - incluindo todo o imenso conjunto das obras cinematográficas que já foram produzidas e também as práticas e discursos que sobre elas se estabelecem - pode ser considerado nos dias de hoje uma fonte primordial e inesgotável para o trabalho historiográfico. A partir de uma fonte fílmica, e a partir da análise dos discursos e práticas cinematográficas relacionados aos diversos contextos contemporâneos, os historiadores podem apreender de uma nova perspectiva a própria história do século XX e da contemporaneidade. De igual maneira, como se verá mais adiante, os historiadores políticos e culturais podem examinar os diversos usos, recepções e apropriações dos discursos, práticas e obras cinematográficas.

Para além deste fato mais evidente de que o Cinema - enquanto 'forma de expressão cultural' especificamente contemporânea - fornece fontes extraordinariamente significativas para os estudos históricos sobre a própria época em que foi e está sendo produzido, uma outra relação fulcral entre História e Cinema pode aparecer através da dimensão deste último como 'representação'. O Cinema não é apenas uma forma de expressão cultural, mas também um 'meio de representação'. Através de um filme representa-se algo, seja uma realidade percebida e interpretada, ou seja, um mundo imaginário livremente criado pelos autores de um filme.

Para o âmbito das relações entre Cinema e História, interessa particularmente a possibilidade de a obra cinematográfica funcionar como meio de representação ou como veículo interpretante de realidades históricas específicas, ou, ainda, como linguagem que se abre livremente para a imaginação histórica. Em um caso, trataremos dos chamados 'filmes históricos' - entendidos aqui como aqueles filmes que buscam representar ou estetizar eventos ou processos históricos conhecidos, e que incluem entre outras as categorias dos 'filmes épicos' e também dos filmes históricos que apresentam uma versão romanceada de eventos ou vidas de personagens históricos. Em outro caso, será possível destacar ainda aqueles filmes que chamaremos de 'filmes de ambientação histórica', aqui considerando os filmes que se referem a enredos criados livremente mas sobre um contexto histórico bem estabelecido.

Ao lado dos 'filmes históricos' e dos 'filmes de ambientação histórica', uma terceira e importante modalidade ainda a ser discutida neste tipo de relação entre o Cinema e a representação histórica é a dos 'documentários históricos' - que podem ser definidos mais 
especificamente como trabalhos de representação historiográfica através de filmes, diferenciando-se dos atrás mencionados filmes históricos seja pelo rigor documental em que se apóiam, seja pelo fato de que neles o fator estético é deslocado para segundo plano e não é quem conduz os rumos da narrativa ou da construção fílmica. Desta maneira, enquanto o 'filme histórico' narra criativamente um evento ou processo histórico, tomando-o para enredo, o 'documentário historiográfico' analisa os acontecimentos à maneira dos historiadores, comparando depoimentos e fontes, sobrepondo imagens da época, analisando situações através da lógica historiográfica e do raciocínio hipotético-dedutivo, e encaminhando uma série de operações que são algo similares àquelas das quais os historiadores lançam mão ao examinar um processo histórico em obra historiográfica em forma de livro. Assim, o fio condutor do 'documentário historiográfico' é essencialmente a análise de eventos e processos históricos, e não a mera narração destes processos mediada pelo mesmo tipo de estetização que aparece nos filmes ficcionais. Vale ainda lembrar que, enquanto o 'filme histórico' oculta as fontes em que se apoiou, o 'documentário histórico' desenvolve-se habitualmente explicitando suas fontes para os espectadores e marcando uma distância clara entre o discurso do cineasta-historiador e estas mesmas fontes (o discurso dos outros, as imagens e documentos de época, e assim por diante). Em suma, ressalvadas as especificidades de cada linguagem e as características pessoais de cada autor, o cineasta-historiador age analogamente ao que faria um historiador tradicional que escreve um livro de História nos dias de hoje.

Em síntese - sobre o 'filme histórico', o 'filme de ambientação histórica', e o 'documentário histórico', entre outros tipos similares que poderiam também ser mencionados - pode-se dizer que estas três modalidades fílmicas relacionadas à História (considerada aqui como objeto de conhecimento) correspondem respectivamente, na Literatura, ao 'romance histórico' propriamente dito, à obra de ficção com ambientação histórica, e às próprias representações historiográficas produzidas pelos historiadores profissionais ou diletantes.

Sobre todos estes tipos de 'filmes de História' (no sentido amplo), é importante ressaltar ainda que eles possuem uma dupla natureza, uma espécie de duplo vínculo em relação à História. Além de serem 'fontes' importantes para a percepção de processos históricos diversificados que se dão na própria época de sua produção, tal como aliás ocorre com os demais filmes (inclusive os de ficção), os 'filmes de História' são também fontes primordiais para o estudo das próprias representações historiográficas. Neste sentido, além de 
ser possível neste tipo de fontes cinematográficas estudar a História (enquanto objeto de conhecimento), é possível estudar a partir deles as próprias representações e concepções historiográficas (isto é, a História enquanto campo de conhecimento), discutindo a Historiografia nos seus diversos níveis. Pode-se dizer que através dos 'filmes de História' de diversos tipos o Cinema começa a penetrar de diversificadas maneiras no próprio mundo dos historiadores, e não apenas no mundo de acontecimentos históricos que os historiadores examinam com algum tipo de distanciamento.

As possibilidades acima apresentadas de relacionar Cinema e representação histórica levam a pensar também em uma terceira relação importante que, agora, aparece através da mediação dos saberes pedagógicos e educativos. O Cinema através de sua produção fílmica, e não apenas dos documentários históricos, também pode ser utilizado para ensinar História ou, mais ainda, para veicular e até impor uma determinada visão da História. Entramos aqui em uma outra possibilidade de apreensão das relações possíveis entre Cinema e História. Tanto os historiadores podem estudar os usos políticos e educacionais que têm se mostrado possíveis através do Cinema, como de igual maneira os pedagogos (e também os professores de história) podem utilizar o Cinema para difundir o saber histórico e historiográfico de uma determinada maneira ${ }^{2}$.

Para além do papel do filme como veículo final de uma determinada representação historiográfica - isto é, como um 'meio' propriamente dito para esta representação historiográfica - é importante ressaltar que a filmagem pode funcionar ainda como 'instrumento de pesquisa' importante para a prática historiográfica, tenha esta como produto final um filme ou um livro. Assim, se o uso do gravador e da fotografia veio trazer instrumentos importantíssimos para os antropólogos e sociólogos dos últimos tempos, as práticas cinematográficas vieram trazer uma contribuição fundamental ao acenarem com a possibilidade do uso filmagem nas pesquisas ligadas às ciências humanas, aqui considerando que a filmagem permite a captação de imagens-som em movimento para posterior análise (por exemplo, o ritual de uma tribo indígena ou as imagens de um determinado distúrbio social).

O Cinema, assim, apresenta-se como tecnologia adicional para a História Oral acrescentando uma nova dimensão à coleta de depoimentos - mas também para outras

${ }^{2}$ Sobre as possibilidades de relacionar Cinema e Ensino de História, veja-se MONTERDE, Historia, cine y enseñanza. Barcelona: Laia, 1986. 
inúmeras modalidades historiográficas como a História da Cultura Material ou a História do Cotidiano (basta pensar na filmagem de estruturas urbanas para posterior análise pelo historiador da cultura material, ou na filmagem de situações da vida cotidiana para interpretação posterior pelo historiador do cotidiano) ${ }^{3}$. A tecnologia cinematográfica, por fim, mostra-se magnífico instrumento para a História Imediata, aqui entendida como aquela modalidade da História em que o historiador participa mais diretamente do próprio processo ou situação histórica que está investigando.

Em vista do que se disse até aqui, cada vez mais a historiografia dos últimos tempos tem se dado conta das múltiplas potencialidades do Cinema simultaneamente como fonte para o estudo da história, como veículo privilegiado para a difusão das próprias representações historiográficas, e como tecnologia auxiliar para a História. Naturalmente que, já que o próprio Cinema é relativamente recente na história, seu uso pela Historiografia também é recente. Além disto, acresce que também não deixa de ser recente mesmo a utilização pela historiografia de fontes não propriamente documentais ou textuais. A primeira metade do século XX, como se sabe, marca precisamente a expansão das concepções de 'fonte histórica', já que trouxe à tona um interesse mais vivo por fontes iconográficas, por fontes da cultura material, pela história oral, e por tantas novas possibilidades de materiais para serem trabalhados pelos historiadores. A fonte fílmica, que aliás integra ao discurso verbal as dimensões da visualidade e da oralidade, enquadra-se compreensivelmente neste mesmo movimento de expansão de temáticas e de possibilidades de novas fontes historiográficas.

Uma última relação possível entre Cinema e História - para além de seu papel como 'expressão', 'representação' e 'tecnologia' - vincula-se ao fato de que o Cinema também pode corresponder a uma 'ação' que interfere na História (não mais a História no sentido de campo do saber, mas a própria História realizada pelos homens na sua vida social). Veremos mais adiante que, do Cinema, podem se apropriar poderes diversos que "agem" na História; e que, de outro lado, o Cinema também pode se apresentar como campo de resistência a diversos poderes instituídos. Por isto, vale dizer que, em todos estes casos, o Cinema tem sido um poderoso 'agente histórico' desde os anos que o viram surgir.

\footnotetext{
${ }^{3}$ É aliás interessante perceber que desde a sua origem o Cinema, nas mãos dos próprios irmãos Lumière, já mostrava este caminho de estreitamento de relações com a História através de filmes que exploravam a possibilidade de registrar cenas da realidade vivida. Um exemplo é a película La sortie du train de la ciotat (1895), onde se registra a cena da saída de operários de uma fábrica, ao final do expediente.
} 
O Cinema apresenta-se como 'agente da história' seja através da Indústria Cultural, seja através das ações estatais e dos diversos usos políticos, seja através da difusão de diversificadas ideologias, ou seja através da resistência a estas mesmas forças. Isto sem contar que - através de uma obra fílmica mais específica - diversos agentes estão freqüentemente atuando de modo bastante significativo na História. Aqui, portanto, o Cinema assume - para muito além de sua dimensão como meio e como objeto de estudo - a função de sujeito da História.

\section{O Cinema como 'agente histórico’}

Acompanhando as dimensões norteadoras atrás citadas, será possível adentrar em seguida a complexa relação entre História e Cinema a partir de alguns ângulos que convém precisar. Discutiremos três dos eixos fundamentais atrás estabelecidos, que permitem avaliar o cinema como 'agente da história', o cinema como 'fonte histórica', e o cinema como meio para produzir uma nova forma de 'representação historiográfica' ou de transmissão do conhecimento histórico.

Em primeiro lugar, consideraremos a idéia de que acima de tudo o Cinema pode ser visto ele mesmo como agente histórico. O Cinema mostra-se um 'agente histórico' importante no sentido de que interfere direta ou indiretamente na História. Ou, mais propriamente, poderíamos acrescentar que o Cinema tem se mostrado um instrumento particularmente importante ou um veículo significativo para a ação dos vários agentes históricos, para a interferência destes agentes na própria História. O Cinema, então, mostra-se como poderoso instrumento de difusão ideológica, ou mesmo como arma imprescindível no seio de um bem articulado sistema de propaganda e marketing. Por isso mesmo, em uma primeira instância, já se mostra bastante interessante para os historiadores contemporâneos a possibilidade de examinar sistematicamente as relações entre Cinema e Poder, o que - como se verá adiante fará da arte fílmica e das práticas cinematográficas um importante objeto de estudo para a História Política (e não apenas para a História Cultural).

Essa relação entre Poder e Cinema é múltipla e igualmente complexa. Desde cedo, as diversas agências associadas aos poderes instituídos compreenderam a importância do 
Cinema como veículo de comunicação, de difusão e até de imposição de idéias e ideologias ${ }^{4}$. Trate-se de um documentário, de um filme de propaganda política, ou de uma obra de ficção cinematográfica, o Cinema tem sido utilizado em diversas ocasiões como instrumento de dominação, de imposição hegemônica e de manipulação pelos agentes sociais ligados ao poder instituído (instituições governamentais, partidos políticos, igrejas, associações diversas), e também por grupos sociais diversos que têm sua representação social junto a estes poderes instituídos. Essa tem sido sem dúvida uma primeira relação política importante a ser considerada.

Por outro lado, o Cinema também conservou obviamente a sua autonomia em relação aos poderes instituídos, e por isso ocorre que também tenha funcionado como Contrapoder. Neste sentido, se o Cinema com sua produção fílmica pode ser examinado como 'instrumento de dominação' e de imposição hegemônica, ele também pode ser examinado como meio de 'resistência'. Daí que as fontes associadas ao Cinema podem ser analisadas tanto como documentação importante para compreensão dos mecanismos e processos de dominação, como também podem ser encaradas como documentação significativa que traz e revela dentro de si as múltiplas formas de resistências, as diversificadas vozes sociais (inclusive as que não encontram representação junto ao Poder Instituído), e de resto os variados padrões de representação associados a uma sociedade.

O Cinema - e a sua realização última que é o Filme - é sempre construção polifônica, para utilizar uma metáfora emprestada à Música. Nele cantam inevitavelmente todas as vozes sociais, não apenas as que invadem a cena através de seus discursos como também as que nela penetram através da imagem. Ainda que uma determinada produção fílmica seja montada para a expressão de um modo de vida que é o de alguma classe dominante, ou ainda que o filme seja empregado como parte de estratégias políticas específicas - e ainda que os diálogos principais postos em cena atendam ou expressem interesses sociais e políticos específicos haverá sempre algo que se impõe ou dá-se a perceber através da imagem e que pode revelar inesperadamente os demais modos de vida, ou algo que se há de impor como contra-discurso e entredito que se constrói à sombra dos diálogos que entretecem o discurso principal.

\footnotetext{
${ }^{4}$ Marc Ferro já observava a este respeito: "Paralelamente, desde que o cinema se tornou uma arte, seus pioneiros passaram a intervir na história com filmes, documentários ou de ficção, que, desde sua origem, sob a aparência de representação, doutrinam e glorificam” (Marc FERRO, Cinema e História, Rio de Janeiro: Paz e Terra, 1992,
} p.13). 
Apenas para dar um exemplo de estudo de caso que permite trazer à tona estas relações, o Cinema apresentou-se no Brasil do Estado Novo com todas estas facetas. Foi utilizado como instrumento de doutrinação política através dos documentários produzidos pelo DIP (Departamento de Imprensa e Propaganda do Governo Vargas), como veículo para a alienação através de alguns filmes e chanchadas de ficção, mas também como instrumento de resistência e contrapoder a partir diversos outros filmes de ficção. Para considerar o caso dos filmes satíricos, é sempre importante lembrar que a obra de humor artístico pode veicular por diversas vezes críticas ao Poder Instituído que não poderiam circular através do discurso “sério". Essas relações várias, por outro lado, podem aparecer em algumas ocasiões dentro de um único filme, o que mostra a potencialidade da obra cinematográfica como produto complexo.

Um filme, enfim, pode se apresentar como um projeto para agir sobre a sociedade, para formar opinião, para iludir ou denunciar. Portanto, um projeto para interferir na História, por trás do qual podem se esconder ou se explicitar desde os interesses políticos de diversas procedências até os interesses mercadológicos encaminhados pela Indústria Cultural. E, certamente, através de um filme podem também agir os indivíduos que representam posições específicas. Lembremos aqui os polêmicos documentários de Michael Moore - como Tiros em Columbine (2002) ou Fahrenheit 9/11 (2004) - onde o autor, valendo-se do gênero Documentário, na verdade o utiliza de uma nova maneira, não apenas para registro e interpretação da realidade como também com vistas a uma explícita e imediata interferência nesta realidade 5 . Assim, ao ocupar a posição de entrevistador, o autor instiga, provoca, assume nitidamente uma posição, impõe situações que querem mudar o curso da realidade examinada. Age, portanto, sobre a História.

\footnotetext{
${ }^{5}$ Em Bowling for Columbine (2002), a pretexto de investigar a fascinação dos americanos pelas armas de fogo, Michael Moore questiona a origem dessa cultura bélica e busca respostas visitando pequenas cidades dos Estados Unidos, onde a maior parte dos moradores guarda uma arma em casa. O ponto de partida é o colégio Columbine, na cidade de Littleton, onde dois adolescentes utilizaram as armas dos pais para matar 14 estudantes e um professor no refeitório. / Em Fahrenheit 9/11 (2004), a pretexto de investigar como os Estados Unidos se tornaram alvo de terroristas por ocasião dos eventos ocorridos no atentado de 11 de setembro de 2001, encaminha-se a denúncia de uma rede de poderes políticos e econômicos que é entretecida através de paralelos entre as duas gerações da família Bush que já comandaram o país, discutindo-se ainda as relações entre o atual Presidente americano, George W. Bush, e Osama Bin Laden.
} 
Naturalmente que, além dos usos políticos voluntários e involuntários, conscientes e inconscientes, os filmes também se apresentam como registro das representações e visões de mundo presentes nas sociedades que os produziram. Tal como se disse, através de uma obra fílmica expressam-se de maneira complexa várias vozes sociais e diversificadas perspectivas culturais. O Cinema, considerado como agente histórico, pode ser por isto compreendido mais propriamente como um feixe de agentes históricos diversos - e se ele permite um estudo sistematizado das relações políticas, permite também um estudo acurado das práticas e representações culturais. Daí seu simultâneo interesse tanto para a História Política como para a História Cultural.

\section{O Cinema como 'fonte histórica'}

Se o Cinema é 'agente da História' no sentido de que interfere direta ou indiretamente na História, ele também é interferido todo o tempo pela História, que o determina nos seus múltiplos aspectos. Vale dizer, o cinema é 'produto da História' - e, como todo produto, um excelente meio para a observação do 'lugar que o produz', isto é, a Sociedade que o contextualiza, que define a sua própria linguagem possível, que estabelece os seus fazeres, que institui as suas temáticas. Por isto, qualquer obra cinematográfica - seja um documentário ou uma pura ficção - é sempre portadora de retratos, de marcas e de indícios significativos da Sociedade que a produziu. É neste sentido que as obras cinematográficas devem ser tratadas pelo historiador como 'fontes históricas' significativas para o estudo das sociedades que produzem filmes, o que inclui todos os gêneros fílmicos possíveis. A mais fantasiosa obra cinematográfica de ficção traz por trás de si ideologias, imaginários, relações de poder, padrões de cultura. Esta afirmação, que de resto também é perfeitamente válida para as obras de Literatura, dá suporte ao fato de que a fonte cinematográfica tem sido utilizada com cada vez mais freqüência pelos historiadores contemporâneos.

O lugar que produz o Cinema é também o lugar que o recebe, de modo que a fonte fílmica pode dar a compreender uma Sociedade simultaneamente a partir do sistema que o produz e do seu universo de recepção. O público consumidor e a crítica inscrevem-se desde já na rede que produz o filme, conjuntamente com os demais fatores que atuam na sua Produção, e isto porque o público receptor é sempre levado em consideração nos momentos em que o 
filme é elaborado. As competências e expectativas do consumo, enfim, são antecipadas no momento em que é produzida a obra cinematográfica, de modo que analisar um filme é analisar também o público que irá consumi-lo.

Com relação a estes e outros aspectos, a fonte cinematográfica, particularmente a fonte fílmica, torna-se evidentemente uma documentação imprescindível para a História Cultural uma vez que ela revela imaginários, visões de mundo, padrões de comportamento, mentalidades, sistemas de hábitos, hierarquias sociais cristalizadas em formações discursivas, e tantos outros aspectos vinculados à de uma determinada sociedade historicamente localizada. Mas como a Indústria Cinematográfica contempla em todas estas instâncias relações de poder - seja no que concerne à sua inserção no universo da Indústria Cultural, seja no que se refere à sua apropriação pelos poderes públicos e privados - é natural que pelos estudos históricos do Cinema se interessem também a História Política, a História Social, e mesmo a História Econômica em sua inserção com estas modalidades historiográficas.

É muito importante para o historiador avançar na compreensão dos poderes que atravessam o Cinema, alguns interferindo diretamente na feitura de filmes. Apenas para nos atermos ao âmbito dos poderes que circulam na esfera da Indústria Cultural, iremos encontrar todo um conjunto de poderes e micropoderes que enredam a feitura de um filme, e isto variando de acordo com os diversos contextos e com as diversas fases da História do Cinema. O Cinema que surge com os irmãos Lumière irá logo empreender uma criativa luta para se transformar de mera tecnologia em Arte, e a partir daí se empenha em construir uma linguagem inteiramente nova. O Cinema que convive com a Televisão, por exemplo, é já outro e deve confrontar-se com a idéia de que seus objetos fílmicos em determinado momento passarão das grandes Telas ao circuito da Televisão (e mais tarde, já nas últimas décadas do século XX, ao circuito da televisão por assinatura e das locadoras do vídeo). Tudo isto interfere na sua feitura, porque a Indústria Cultural almeja explorar todas as mídias e mercados, e neste sentido seus produtos devem ser polivalentes e adaptativos com vistas à geração de lucros crescentes.

Haverá mesmo filmes feitos especialmente pela Televisão, e outros previstos para gerarem séries para a Televisão. Quando se escreve um roteiro de filme para televisão, devese antecipar as reações de um telespectador que não está mais preso por duas horas dentro de um recinto fechado de sessão cinematográfica para a qual já comprometeu o valor de um 
ingresso. Esse novo espectador que assiste na televisão a um filme - seja um filme que já percorreu o circuito das salas de cinema ou um filme tipicamente televisivo - possui literalmente nas mãos um novo poder: o zapping - esta possibilidade de apertar um botão no controle remoto e mudar o canal. Os roteiros, desta forma, não podem ser concebidos livremente, pois desde o instante da sua gestação já sofrem a presença desta formidável multidão de micropoderes. É preciso capturar a atenção do espectador comum, e neste sentido as emissoras pressionarão roteiristas para fazerem cortes nos seus roteiros de modo a conseguirem mais excitação, mais suspense, por vezes maior velocidade ou maior nível de adaptação à competência do espectador comum. Desta maneira, os grandes interesses das emissoras e as pequenas expectativas do telespectador comum se enredam para pressionar a feitura do filme. Em operação inversa, ocorre ao historiador que ele pode partir de um filme aqui tomado como fonte histórica - para precisamente desvendar esta rede de poderes e micropoderes, de expectativas de mercado e de competências espectadoras, de padrões culturais impostos pela mídia e de representações culturais que surgem espontaneamente. $\mathrm{Ou}$ seja, partindo de um produto, ele estará apto a decifrar a sociedade que o produziu.

Em vista deste mundo de novas possibilidades historiográficas, examinaremos nos próximos parágrafos os diversos tipos de fontes relacionadas com o Cinema, e de que podem ser valer os historiadores do mundo contemporâneo. Será necessário considerar aqui toda uma gama de fontes importantes, desde aquelas geradas para e pela produção de um filme - como roteiros, sinopses, cenários, registros de marcações de cenas, mas também contratos, propagandas, críticas de cinema, receitas e despesas de produção - até aquela que é a fonte por excelência: o filme.

De fato, no que se refere às fontes primárias para o estudo da História do Cinema, ou então da História através do Cinema, a primeira fonte mais óbvia a se considerar é o próprio filme, o produto final da arte cinematográfica. Neste sentido, um ponto de partida metodológico para examinar sistematicamente a relação entre Cinema e História deve vir ancorado na compreensão de que o filme, pretenda ele ser imagem ou não da realidade, e enquadre-se dentro de um dos gêneros documentários ou dentro de um dos gêneros de ficção, é em todos estes casos História. Não importa se o filme pretende ser um retrato, uma intriga autêntica, ou pura invenção, sempre ele estará sendo produzido dentro da História e sujeito às 
dimensões sociais e culturais que decorrem da História - isto independente da vontade dos que contribuíram e interferiram para a sua elaboração.

Assim, o mais fantasioso filme de ficção científica não expressa senão as possibilidades de uma realidade histórica, seja como retratação dissimulada, como inversão, como tendência discursiva que o estrutura, como visão de mundo que o informa e que o enforma (que lhe dá forma), e assim por diante. É por isto, tal como se observou antes, que é sempre possível dizer que a ficção, por mais criativa e imaginativa que seja, permite em todos os casos uma aguda leitura da realidade social e histórica, o que implica em dizer que o historiador ou o analista da fonte documental cinematográfica sempre poderá almejar enxergar por trás de um filme algo da sociedade que o produziu, e que poderá analisar a fonte fílmica como um produto complexo que se vê potencializado pelo fato de que para ela confluem diversos tipos de linguagens e materiais discursivos denunciadores de uma época, de caminhos culturais específicos, de agentes sociais diversos, de relações de poder bem definidas, de visões de mundo multi-diversificadas.

Apenas para registrar um exemplo, a Los Angeles do século XXI que nos é apresentada em Blade Runner (1982) - um filme que intermescla os gêneros da ficção científica e do filme policial - é uma Los Angeles certamente fictícia, imaginada pelo romancista de cujo texto foi extraído o enredo e pelo roteirista da película ${ }^{6}$. Contudo, uma análise acurada poderia nos mostrar como são projetadas nesta Los Angeles imaginária vários dos medos típicos dos americanos ou do homem moderno, de modo geral.

A Los Angeles de Blade Runner, com seu submundo formado por ruas estreitas e poluídas habitadas por uma população que se reparte em etnias e dialetos, e que se vê contraponteado por prédios de centenas de andares e por uma sofisticada tecnologia, é certamente o espaço imaginário de projeção de alguns dos grandes medos americanos: a

\footnotetext{
${ }^{6}$ Blade Runner - filme de Ridley Scott produzido em 1982 com base no romance de Philip K. Dick - traz uma visão apocalíptica ambientada no início do século XXI, época em que uma grande corporação havia desenvolvido um andróide que mais forte e ágil que o ser humano. Estes "replicantes" eram utilizados como escravos na colonização e exploração de outros planetas, até que um grupo dos robôs mais evoluídos provoca um motim em uma colônia fora da Terra, e a partir deste incidente os replicantes passam a serem considerados ilegais na Terra. A partir de então, policiais de um esquadrão de elite, conhecidos como Blade Runner, são orientados para exterminar qualquer replicante encontrado na Terra. Até que, em 2019, quando cinco replicantes chegam a Terra, um ex-Blade Runner é encarregado de caçá-los.
} 
poluição, a violência, a escassez alimentar, a opressão tecnológica, a presença de migrantes vindos de outros países, a ameaça da perda de uma identidade propriamente "americana", os desastres ecológicos que no filme aparecem sob a forma de uma chuva ácida com a qual têm de conviver os habitantes deste futuro imaginário. Os replicantes - andróides criados pelos homens do futuro - expressam com sua revolta os temores dos homens de hoje diante de uma tecnologia que pode sair do controle, da criatura que ameaça o criador - tema que de resto sempre foi caro à ficção científica já clássica.

De igual maneira, na temática de um mundo dominado e controlado por uma megacorporação, aparecem nos labirintos discursivos de Blade Runner os receios diante de um futuro onde a Empresa Capitalista passa a assumir o papel de Estado e a ter plenos poderes sobre a vida e a morte de todos os indivíduos - o que, em última instância, traz à tona o temor diante da possibilidade da perda de liberdade individual. Para além disto, as relações entre os homens e a Memória, na qual se apóiam para a construção de sua identidade individual e que no entanto lhes é tão inconsistente, são trazidas a nu na famosa cena que se refere a uma replicante que não possui sequer a consciência de ser uma replicante (isto é, não-humana), e que se depara com a cruel realidade de que a memória que foi nela implantada não corresponde a nenhuma vivência efetiva ${ }^{7}$. As relações com Deus e a Morte por fim, aparecem na parábola que dá forma geral ao filme através de um enredo onde os replicantes procuram obstinadamente os seus criadores na esperança de prolongarem a própria vida, e que traz como um dos desfechos a cena da Criatura que termina por assassinar o seu Criador, evocando as intrincadas relações psicológicas que permeiam desde sempre as relações entre o homem e Deus através das realidades religiosas por ele mesmo engendradas na história real.

\footnotetext{
${ }^{7}$ No filme Blade Runner, os replicantes não possuem memória, visto que já nascem prontos, preparados que são para durarem apenas quatro anos. No caso da replicante mencionada (Rachel), tratava-se ainda de um caso especial: uma replicante que fora programada para pensar que era humana, e que por isso possuía uma memória implantada que acreditava corresponder a vivências efetivas (e que era reforçada por fotografias que ela possuía e que acreditava serem fotos suas de infância). O filme deixa no ar, aliás, a possibilidade de que o próprio Deckard (o caçador de andróides) poderia ser ele mesmo um replicante que acreditava ser humano, tal como a replicante Rachel. Como saber, enfim, se as memórias que possuímos são realmente nossas, correspondentes a experiências efetivas que um dia foram vividas por nós (?) - tal é a reflexão percorrida nas cenas de Blade Runner que evocam as relações dos personagens - humanos ou replicantes - com a Memória. A este propósito, cumpre lembrar que Ridley Scott procurou dotar seu filme de uma série de ambigüidades, permitindo que dele surjam diferentes leituras.
} 
Por fim, Blade Runner levanta em diversas ocasiões um questionamento típico desta nossa época que entremeia o Real e o Virtual e que, para além disto, ensejou perturbadoras reflexões filosóficas sobre a desconstrução do sujeito, esta desconstrução tão típica da pós-modernidade e que vem abalar fortemente as certezas do homem contemporâneo em relação à sua própria existência objetiva ${ }^{8}$. Eis, portanto, um exemplo entre tantos que poderiam ser dados de que toda a ficção está sempre impregnada da realidade vivida, seja com a intenção ou sem a intenção de seu autor.

É por isto que, a princípio, qualquer filme - seja um policial, um filme de ficção científica, uma pornô-chanchada, um filme de amor - pode ser constituído em fonte pelo historiador que esteja interessado em compreender a sociedade que o produziu e que o tornou possível como obra. Desnecessário dizer que um filme ambientado na Idade Média que seja elaborado hoje falará ao historiador muito mais sobre a Idade Contemporânea do que sobre a Idade Média. Seria de se perguntar o quanto o filme Cruzada de Ridley Scott (2005) - que acompanha a narrativa de uma cruzada medieval ocorrida em 1185 - fala-nos por exemplo do impacto da Guerra do Iraque e de outros confrontos contemporâneos envolvendo nações ocidentais e o mundo islâmico. Ou, para lembrar outro filme de Scott, até que ponto $O$ Gladiador (2004) - ao abordar o Império Romano - não nos fala do Império Americano, do Jogo de Poder, da corrupção e decadência?

É ainda oportuno lembrar que os filmes também podem ser trabalhados em série, e não apenas a partir de análises individualizadas de seus discursos e de seu enredo. Pode-se estudar a evolução de interesses temáticos a partir de um levantamento geral de obras fílmicas em um determinado período. Se os tempos recentes mostram a renovação de interesses por filmes ambientados na Idade Média ou em tempos antigos, isso certamente diz algo ao historiador sobre o atual contexto sócio-cultural, ou mesmo político, que permitiu a renovação deste interesse. Com a produção ligada ao Cinema ocorre, de resto, o que também se verifica para a produção literatura ou artística em geral. A emergência de determinado tipo de obras, os temas que por elas circulam, o seu vocabulário, as novidades formais que se tornam possíveis ... tudo isto nos fala ainda mais dos receptores da obra do que de seus próprios autores individualizados.

\footnotetext{
${ }^{8}$ Neste sentido, Blade Runner prenuncia uma discussão sobre o verdadeiro estatuto da 'realidade' que mais tarde seria a temática de base de outro grande marco do Cinema Americano, o filme Matrix (2003).
} 
As possibilidades de fontes históricas relativas ao Cinema não se esgotam nesta obra final que é o filme propriamente dito. Para além desta fonte mais óbvia, e que pode ser examinada sob sua forma de registro em Vídeo, é preciso considerar ainda que a fonte fílmica gera outros tipos de fontes como substratos, etapas e instrumentos de trabalho. Por exemplo. O 'Roteiro' mostra-se como um tipo de transposição literária do filme, que terá sido em algum momento tanto um instrumento de trabalho para os produtores do filme, como terá se convertido em outro momento em obra literária por si mesma, posta à venda para a leitura de interessados. Este tipo de fonte também apresenta grande utilidade para o historiador e estudiosos de Ciências de Comunicação que estudam o Cinema. Naturalmente que os métodos de análise que se direcionam para o 'filme' na sua forma de imagens projetadas na tela - e que deste modo se apresenta como uma obra integral que incorpora diversas linguagens devem ser diferenciados dos métodos a serem empregados para a análise do Roteiro, transposição do enredo e diálogos do filme para o texto escrito.

Para além disto, outros tipos de substratos de filmes também podem ser considerados, como a 'Sinopse' - que consiste em um tipo especializado de Resumo do filme, e que se diferencia radicalmente do Roteiro pelo seu caráter breve e sintético. Por outro lado, é preciso ainda considerar que o Filme também gera documentação sobre o Filme. Por exemplo, a Crítica deixa registros textuais de suas leituras sobre filmes específicos através de 'Crônicas Especializadas', normalmente publicadas em Jornais e Revistas. Este tipo de fonte também deve ser abordado pelo historiador do Cinema, com a plena consciência de que neste caso ele não estará mais estudando o filme como fonte direta, mas sim examinando um discurso que se estabelece sobre o filme. Os depoimentos dos próprios autores e envolvidos na produção do filme também podem ser enquadrados nesta modalidade de fontes sobre o Cinema, e um outro substrato possível são as propagandas sobre o produto cinematográfico, seja a propaganda sobre o filme que vai às telas de cinema (ou de televisão, posteriormente), seja a propaganda sobre o filme convertido em vídeo para circular nas chamadas locadoras.

Há ainda a documentação propriamente dita sobre Cinema (no sentido de documentação registrada através da escrita). Tal como já se disse o Cinema também gera apropriações, manipulações e resistências. Estas relações, que permeiam a própria interação entre História e Cinema, também geram inúmeros tipos de documentação que podem ser utilizados pelos historiadores. Pode-se estudar por exemplo a documentação oficial, 
institucional e governamental sobre a produção cinematográfica: Legislação sobre a normatização e controle do Cinema, documentos da Censura, e assim por diante. Apenas para dar um exemplo, os sucessivos governos brasileiros exerceram cada qual um tipo de política cultural para a produção cinematográfica; alguns, como o governo do Estado Novo, criaram mesmo órgãos para produzir filmes para fins de Propaganda Governamental, para a difusão de ideologias, e assim por diante. O Cinema, enfim, está sujeito a este tipo de apropriações, embora ao mesmo tempo tem um grau de autonomia enquanto obra de arte que deve ser considerado.

Fontes ensaísticas sobre o Filme, escritas nos vários períodos da História do Cinema, também podem revelar como o Cinema tem sido visto pela Sociedade, por setores específicos desta sociedade, e por agentes históricos e artísticos vários. Desta forma, os Ensaios sobre o Cinema podem ser tomados como fontes para a análise das várias visões de mundo sobre o Cinema. Assim, por exemplo, diversos cineastas escreveram textos importantes sobre o Cinema, como Jean Epstein ${ }^{9}$, Jean Renoir ${ }^{10}$, Serguei Eisenstein ${ }^{11}$, Jean-Claude Carrière ${ }^{12}$, François Truffaut ${ }^{13}$, e tantos outros. Da mesma forma, outros escreveram autobiografias que certamente elucidam suas relações com o Cinema, bem como aspectos de sua inserção como cineastas em uma sociedade produtora e consumidora de filmes. Entre estes podemos citar Luís Buñuel ${ }^{14}$ e Frederico Fellini ${ }^{15}$, que também nos oferece outro exemplo de fonte importante para compreender o pensamento, as práticas e as representações dos autores de filmes: a Entrevista ${ }^{16}$. É também o caso das entrevistas de François Truffaut ${ }^{17}$. Todos estes tipos de fontes podem ser trabalhados pelos historiadores em conexão com fontes fílmicas

\footnotetext{
${ }^{9}$ Jean EPSTEIN, "O Cinema e as Letras Modernas" (1921) In: XAVIER, Ismail (Org.). A Experiência do Cinema. Rio de Janeiro: Graal, 1991.

${ }^{10}$ Jean RENOIR, Escritos sobre o Cinema: 1926-1971, Rio de Janeiro: Nova Fronteira, 1990.

${ }^{11}$ (1) Serguei EISENSTEIN, A Forma do Filme, Rio de Janeiro: Jorge Zahar editor, 1990. (2)

Serguei EISENSTEIN, O Sentido do Filme. Rio de Janeiro: Jorge Zahar editor, 1990.

${ }^{12}$ Jean-Claude CARRIÈRE, A Linguagem Secreta do Cinema. Rio de Janeiro: Nova Fronteira, 1995.

${ }^{13}$ François TRUFFAUT, Os filmes de minha vida. Rio de Janeiro, Nova Fronteira, 1989.

${ }^{14}$ Luis BUÑUEL, Meu último suspiro, Rio de Janeiro: Nova Fronteira, 1982.

${ }^{15}$ Frederico FELLINI, Fellini por Fellini, Lisboa: Don Quixote, 1985.

${ }^{16}$ Frederico FELLINI, Eu sou um grande mentiroso, entrevista a Damien Pettigrew, Rio de Janeiro, Nova Fronteira, 1995.
}

${ }^{17}$ François TRUFFAUT. Truffaut / Hitchcock - Entrevistas. Brasiliense, São Paulo, 1986. 
propriamente ditas, apenas para considerar os textos de autoria dos próprios produtores diretos de filmes ${ }^{18}$.

\section{O Cinema como 'representação histórica'}

Dizíamos ao princípio deste ensaio que um importante campo de interesse em torno das relações entre Cinema e História refere-se ao fato de que o próprio Cinema, através dos filmes produzidos, presta-se também à representação historiográfica. Naturalmente que, para adentrar a questão, é importante aprofundar a reflexão a respeito do que são os 'filmes de História', sempre lembrando que a Representação Historiográfica não é a própria História, mesmo no que concerne aos chamados documentários históricos. Assim, tal como já se disse, devem ser consideradas como fontes fílmicas interessantes para o estudo das relações entre Cinema e Representação Historiográfica não apenas os documentários historiográfícos (representações historiográficas, propriamente ditas), mas também quaisquer filmes de ambientação histórica, e neste caso se enquadram, para além dos 'filmes históricos' romanceados, mesmo os filmes de pura ficção construídos sobre um contexto histórico bem definido. De fato, estes vários tipos podem ser considerados em certa medida como um tipo de 'representação histórica' atravessado pela ficção (ou um tipo de ficção atravessado pela 'representação histórica').

Neste momento final, no intuito de iluminar os usos do cinema como meio mais direto para a representação historiográfica, examinaremos os gêneros de filmes que atrás definimos, em sentido mais amplo, como 'filmes de História', e que trazem no seu enredo e na sua temática um fundo histórico que seja, quando não um projeto de representação da própria História no que se refere a algum evento ou processo considerado. Os exemplos escolhidos neste momento referem-se mais particularmente aos filmes históricos relacionados com a História do Brasil. Mostraremos algumas situações bem distintas de filmes que pertencem a gêneros cinematográficos diferenciados, embora todos se refiram a algum processo, evento ou

\footnotetext{
${ }^{18}$ Já nem mencionaremos a vasta literatura ensaística e de crítica cinematográfica que trazem a nu as diversas representações. visões de mundo e análises individuais sobre o cinema ou sobre filmes específicos, e que podem ir desde as obras filosóficas de Gilles DELEUZE até as crônicas diárias sobre a produção fílmica que são publicadas nos periódicos todos os dias.
} 
personagem da História do Brasil. Os filmes escolhidos para essa exemplificação metodológica são: Jango (1984), Carlota Joaquina (1995), Xica da Silva (1976), Guerra de Canudos (1997), Memórias do Cárcere (1983) e Pra Frente Brasil (1983). Cada filme aqui tomado como exemplo, conforme se verá, corresponde a um tipo de representação historiográfica distinta através da linguagem cinematográfica.

Jango (1984) é o típico exemplo de documentário de cunho historiográfico e político ${ }^{19}$. Isto quer dizer que o filme se propõe a fazer explicitamente uma representação historiográfica dos processos e acontecimentos que pretende descrever - no caso a História do Brasil perceptível a partir da figura do ex-presidente da República João Goulart. Este tipo de documentário, naturalmente, deve ser examinado como se examina uma montagem historiográfica qualquer (um trabalho de historiografia, por exemplo), considerando-se, é claro, as especificidades da própria linguagem cinematográfica e a necessidade de um certo viés narrativo que é implícita a um tipo de filme que pretende alcançar o grande público. Jango, como qualquer documentário elaborado com seriedade, é construído a partir de determinadas fontes. Isto não impede, naturalmente, que o analista o avalie como construção historiográfica, inclusive atravessada por uma ideologia que pode ser decifrada (mas que, involuntariamente, traz nas suas vozes internas diversos discursos políticos, e logo, novas ideologias na voz dos vários personagens que são expostos no filme).

Muito diferente de Jango é o filme Xica da Silva (1976). Este filme, como Jango, também foi construído com apoio em fontes históricas. Na verdade, o filme foi construído sobre uma única fonte histórica: a Crônica de Joaquim Felício dos Santos, um cronista da

\footnotetext{
${ }^{19} \mathrm{O}$ gênero de filme categorizado como Documentário - não necessariamente o documentário historiográfico surge de maneira mais consolidada na Inglaterra nos anos 1930 com o trabalho de John Grierson (1898-1972) sendo o seu filme Drifters (1929) a obra que marca o "movimento documentarista britânico". Uma curiosidade é que no seu texto "First principles of documentary", Grierson definiu o documentário como "tratamento criativo da realidade" (HARDLY, Forsyth, Grierson on documentary, Los Angeles: University of Califórnia Press, 1966, p.145-156). Destaque-se ainda que desde os irmãos Lumière - que filmaram entre 1895 e 1896 pequenas películas como A Saída da Fábrica ou A Chegada do Trem - tinha-se já um embrião do gênero documentário, considerando-se ainda que, em seguida, já no início do século, diversos operadores empenharam-se em filmar atualidades, noticiários ou cenas de viagens.
} 
segunda metade do século XIX, sobre a célebre personagem do Brasil escravocrata que ficou conhecida como Xica da Silva. Pode-se dizer que este filme é uma montagem livre, esteticamente orientada (o objetivo é mais entreter do que documentar) sobre uma crônica histórica. O filme segue livremente, desta forma, o fio narrativo do próprio cronista do século XIX, mas desconstruindo esta narrativa em vista de um resultado cinematográfico. É evidente que temos aqui um efeito de realidade distinto daquele que pretende obter o roteirista de Jango.

Guerra dos Canudos (1897) é também um exemplo de narrativa cinematográfica que se baseia em episódio retratado por uma fonte de época, a crônica jornalística Os Sertões de Euclides da Cunha. Contudo, trata-se de uma elaboração mais livre, onde não é seguido propriamente o fio narrativo do cronista. Além disto, a fonte primária de referência é de outro cunho, que não a crônica tradicional, mas sim uma crônica jornalística que intermescla trechos ensaísticos bem fundamentados em documentação diversa. Mas por outro lado, temos uma diferença importante em relação aos filmes anteriores, que giravam em torno de uma figura histórica. Canudos não gira em torno da figura de Antônio Conselheiro tomado como eixo narrativo central - tem-se aqui uma narrativa multifocada a partir de diversos atores, inclusive alguns construídos ficticiamente embora a partir de um contexto histórico mais rigoroso. Trata-se, conforme se Vê, de uma representação histórica e cinematográfica complexa.

Outro filme histórico que se destacou nos últimos anos, de teor completamente distinto, foi Carlota Joaquina - Princesa do Brasil (1995). Este filme é o que poderíamos chamar de ficção histórica. Os personagens centrais têm uma existência histórica concreta, mas o enredo é na verdade construído com liberdade ficcional, embora seguindo determinados balizamentos históricos. Este filme na verdade foi elaborado a partir do Romance homônimo de João Felício dos Santos. Esta obra em que se baseia enquadra-se no gênero literário que pode ser denominado 'romance histórico'. O gênero cinematográfico 'ficção histórica', na verdade, corresponde precisamente ao gênero literário conhecido como 'romance histórico', do qual a Literatura nos dá inúmeros exemplos. Não pode ser exigido, neste caso, uma fidedignidade à qual teve de se ater o documentário histórico Jango (que seria, grosso modo, a contrapartida de um ensaio de historiografia profissional). 
Um exemplo singular é o filme Memórias do Cárcere (1983). Neste caso, temos uma narrativa cinematográfica construída sobre uma narrativa memorialística. $\mathrm{O}$ filme refere-se à vida do escritor Graciliano Ramos, particularmente ao período de sua reclusão à prisão por motivos políticos na ocasião do Estado Novo. Mas agora o texto básico que informa o roteiro é um livro de Memórias, escrito pelo próprio Graciliano Ramos, e que recebe o mesmo título. Temos então mais um caso de obra cinematográfica construída sobre uma única fonte primária de natureza literária, mais especificamente um livro de memórias auto-referenciado (que marca sua distância em relação ao exemplo que já vimos anteriormente, e que era a fonte primária de natureza cronística porém referenciada em um personagem que não se confunde com o narrador). É claro que este tipo de representação historiográfica traz consigo suas próprias singularidades, e a obra fílmica elaborada sobre este tipo de fonte literária também terá suas próprias especificidades.

Um último exemplo, completamente distinto dos anteriores, pode ser demonstrado com o filme Pra Frente Brasil (1983). O que se tem aqui é uma ficção inteiramente livre sobre um contexto histórico determinado: o da repressão imposta pela Ditadura Militar durante os chamados "anos de chumbo" da República Brasileira. O objetivo central do filme é denunciar as práticas militares e para-militares do período, cujo mais vergonhoso desdobramento foi a tortura imposta contra os prisioneiros políticos. O filme, contudo, é construído em torno da ficção de um inocente que teria sido confundido com um terrorista e que recebe em vista disto o tratamento que, historiograficamente se sabe, era dispensado aos presos políticos diversos. O personagem fictício é um indivíduo comum, que poderia ser qualquer um - daí a sua força dramática desde as primeiras cenas. Aqui, o que se tem é uma ambiência histórica muito precisa - a dos tempos da cruel repressão militar, contraponteada ironicamente pela euforia com a Copa do Mundo - mas a narrativa construída é de caráter ficcional. Os personagens não são históricos, embora a ambiência contextual o seja.

Todos estes filmes são fontes em diversos sentidos. Eles são fontes para estudar o período em que foram produzidos, permitindo decifrar ideologias e vozes sociais diversas. Mas são também fontes para o estudo dos tipos distintos de representações historiográficas, pois cada qual se refere de uma maneira específica a algum elemento histórico. Por fim, todos estes filmes podem ser utilizados como instrumentos para a mediação na transmissão do conhecimento histórico (através do Ensino, por exemplo), seja para examinar os processos e 
eventos aos quais eles se referem no plano narrativo, seja para examinar as visões de mundo historicamente localizadas que eles trazem ao nível da produção do sentido. Ou seja, a partir destes filmes é possível estudar tanto História como Historiografia.

Estes exemplos, a título meramente demonstrativo de suas potencialidades, dão a perceber como é importante compreender, para cada caso, o gênero de representação cinematográfica (o tipo de filme - documentário, ficção, etc) na sua conexão com as modalidades de representação historiográfica que são tomadas como fontes para a recuperação da época e dos acontecimentos (uma crônica, uma obra de historiografia, fontes de época).

Cinema e História, enfim, estão destinados a uma parceria que envolve intermináveis possibilidades. O Cinema enquanto 'forma de expressão' será sempre uma riquíssima fonte para compreender a realidade que o produz, e neste sentido um campo promissor para a História, aqui considerada enquanto área de conhecimento. Como 'meio de representação', abre para esta mesma História possibilidades de apresentar de novas maneiras o discurso e o trabalho dos historiadores, para muito além da tradicional modalidade da literatura que se apresenta sob a forma de livro. E, por fim, agora considerando a História como o vasto universo dos acontecimentos que afetam os homens ou que são por eles impulsionados, o Cinema apresenta-se certamente como um dos grandes agentes históricos da contemporaneidade. O Cinema interfere na História, e com ela se entrelaça inevitavelmente.

\section{Referências}

BAKHTIN, Mikhail. Marxismo e Filosofia da Linguagem. São Paulo: Hucitec, 1981.

BAKHTIN, Mikhail. Questões de literatura e estética. São Paulo: Hucitec, 1993.

BAUDRILLARD, Jean. Simulacro e simulação. Lisboa: Relógio d’Água, 1991.

BAZIN, André. O Cinema - ensaios. São Paulo, Brasiliense, 1991.

BERNARDET, Jean-Claude. O autor no cinema. São Paulo: Brasiliense / Edusp, 1994.

BUÑUEL, Luis. Meu último suspiro. Rio de Janeiro: Nova Fronteira, 1982. 
BUKATMAN, Scott. Blade Runner. London: BFI Modern Classics, 1997.

CARRIÈre, Jean-Claude. A Linguagem Secreta do Cinema. Rio de Janeiro: Nova Fronteira, 1995.

DELEUZE, Gilles. A imagem-movimento. São Paulo: Editora Brasiliense, 1985.

EISENSTEIN, Serguei. A Forma do Filme. Rio de Janeiro: Jorge Zahar editor, 1990.

O Sentido do Filme. Rio de Janeiro: Jorge Zahar editor, 1990.

EPSTEIN, Jean. "Le Cinematographe Vu de l'Etna” In Écrits sur le Cinéma, Tome I, 1927-1947.

Cinéma Club / Seghers, Paris: 1974, p.131-168.

EPSTEIN, Jean. "O Cinema e as Letras Modernas" (1921) In: XAVIER, Ismail (Org.). A

Experiência do Cinema. Rio de Janeiro: Graal, 1991.

FELLINI, Frederico. Fellini por Fellini. Lisboa: Don Quixote, 1985.

FELLINI, Frederico. Eu sou um grande mentiroso, entrevista a Damien Pettigrew. Rio de Janeiro: Nova Fronteira, 1995.

FERRO, Marc. Cinema e História, Rio de Janeiro: Paz e Terra, 1992.

HARDLY, Forsyth. (ed.). Grierson on documentary. Los Angeles: University of Califórnia Press, 1966.

MARDER, Elissa. “Blade Runner's Moving Still” In Camera obscura, n. 27, p. 88-107, 1991.

MONTERDE, J. E. Historia, cine y enseñanza. Barcelona: Laia, 1986.

RENOIR, Jean. Escritos sobre o Cinema: 1926-1971. Rio de Janeiro: Nova Fronteira, 1990.

TRUFFAUT, François. Os filmes de minha vida. Rio de Janeiro: Nova Fronteira, 1989.

TRUFFAUT, François. Truffaut/Hitchcock - Entrevistas. São Paulo: Brasiliense, 1986.

XAVIER, Ismail (Org.). A Experiência do Cinema. Rio de Janeiro: Graal, 1991.

ZUMTHOR, Paul. A Letra e a Voz. São Paulo: Cia. das Letras, 1993.

Obras fílmicas citadas neste ensaio:

1 - Bowling for Columbine (EUA: 2002). Direção: Michael Moore. Produção: Charles Bishop, Jim Czarnecki, Michael Donovan, Kathleen Glynn e Michael Moore. Roteiro: Michael Moore. Distribuidora: Metro-Goldwyn-Mayer / United Artists. Modalidade: Documentário. Duração: 120 minutos.

2 - Fahrenheit 9/11 (EUA: 2004). Direção: Michael Moore. Produção: Charles Bishop, Jim Czarnecki, Michael Donovan, Kathleen Glynn e Michael Moore. Roteiro: Michael Moore. 
Distribuidora: Metro-Goldwyn-Mayer / United Artists. Modalidade: Documentário. Duração: 112 minutos.

3 - Blade Runner (EUA: 1982). Direção: Ridley Scott. Produção: Michael Deeley. Roteiro: Hampton Francher e David Webb Peoples, baseado em livro de Philip K. Dirk. Distribuidora: Columbia Tristar / Warner Bros. Modalidade: Ficção Científica. Duração: 118 m.

4 - Cruzada (Kingdom of Heaven) (EUA: 2005). Direção: Ridley Scott. Roteiro: Ridley Scott. Distribuidora: Fox Films. Modalidade: Drama. Duração: 145 minutos.

5 - Gladiador (EUA: 2005). Direção: Ridley Scott. Produção: David H. Franzoni, Steven Spielberg e Douglas Wick. Roteiro: David Franzoni, John Logan e William Nicholson. Distribuidora: DreamWorks / Universal Pictures. Modalidade: Épico. Duração: 155 m.

6 - Matrix (EUA: 2003). Direção: Andy Wachowski e Larry Wachowski. Produção: Grant Hill e Joel Silver. Roteiro: Andy Wachowski e Larry Wachowski. Distribuidora: Warner Bros. Modalidade: Ficção Científica. Duração: 129 minutos.

7 - Sonhos (EUA / JAPÃO: 1990). Direção: Akira Kurosawa e Ishirô Honda. Produção: Mike Y. Inoue e Hisao Kurosawa. Roteiro: Akira Kurosawa. Distribuidora: Warner Bros. Modalidade: Drama. Duração: 119 minutos.

8 - Carlota Joaquina - Princesa do Brasil (Brasil: 1995). Direção: Carla Camurati. Roteiro: Carla Camurati e Melanie Dimantas. Distribuidora: Europa/Carati. Modalidade: Ficção histórica baseada em romance histórico (o livro homônimo de João Felício dos Santos). Duração: 105 minutos.

9 - Guerra dos Canudos (Brasil: 1997). Direção: Sérgio Rezende. Roteiro: Sérgio Rezende e Paulo Halm. Distribuidora: Colúmbia Tristar. Modalidade: Épico Histórico. Duração: 165 minutos.

10- Jango (Brasil: 1984). Direção: Sílvio Tender. Roteiro: Sílvio Tender e Maurício Dias. Distribuidora: Caliban. Modalidade: Documentário histórico. Duração: 117 minutos.

11- Memórias do Cárcere (Brasil: 1983). Direção: Nélson Pereira dos Santos. Roteiro: Nélson Pereira dos Santos. Distribuidora: Rio Filmes. Modalidade: Narrativa cinematográfica construída sobre narrativa memorialística. Duração: 180 minutos.

12- Pra Frente Brasil (Brasil: 1997). Direção: Roberto Farias. Roteiro: Roberto Farias. Distribuidora: Politel. Modalidade: Ficção sobre contexto histórico definido. Duração: 105 m.

13- Xica da Silva (Brasil: 1976). Direção: Cacá Diegues. Roteiro: Cacá Diegues e João Felício dos Santos. Modalidade: Livre narrativa sobre crônica de época (a crônica oitocentista de Joaquim Felício dos Santos). Duração: 120 minutos. 